\title{
Investigating the effect of Arctic sea routes on the global maritime container transport system via a generalized Nash equilibrium model
}

\author{
Wang Yangjun, Zhang Ren, Ge Shanshan \& Qian Longxia \\ College of Meteorology and Oceanography, National University of Defense Technology, Nanjing, China
}

\begin{abstract}
This paper proposes a generalized Nash equilibrium model to investigate if Arctic routes can be used as a "relief valve" for current intercontinental sea routes. This model is presented as a Stackelberg form, where the shipping companies correspond to the leaders and the customers correspond to the followers. The competition among shipping companies (leaders), which seek to maximize their profits, can be represented as a generalized Nash equilibrium and solved by the alternating direction method of multipliers algorithm, based on penalization. On the basis of the competition results, the customers (followers) choose the optimal shipping companies; this results in the allocation of container volumes on different sailing routes, which can be described by a logit-type multi-path assignment model. Different scenarios in our modelling show that as shipping speeds decrease through the use of Arctic sea routes, company profits increase. In particular, as navigable days on the Northern Sea Route (NSR) increase, the container trade will increasingly tilt towards this route and shipping companies using it will gain more profits than they did before the opening of this route. At the same time, the proportion of container volume through the Suez Canal will be reduced because it will be less profitable.
\end{abstract}

\section{KEYWORDS}

Container shipping; Stackelberg game model; global warming; Northern Sea Route; Northeast Passage

\section{ABBREVIATIONS}

LKM: Liu \& Kronbak's model NSR: Northern Sea Route; TEU: 20-foot equivalent unit, a unit of cargo capacity used to describe the capacity of container ships and container terminals

\section{Introduction}

As the backbone of international trade, maritime transportation accounts for about $80 \%$ of the volume transported in world trade (Talley \& Ng 2013; UNCTAD (United Nations Conference on Trade and Development) 2013). Following the openings of the Suez and Panama canals, in 1869 and 1914, respectively, there have been few momentous changes to the world maritime shipping system (Omre 2012) Container shipping, which revolutionized shipping in the 1950s and 1960s, has become crowded. For example, the route via the Suez Canal (Fig. 1), the maritime hub linking Europe and Asia, is likely to reach saturation in the coming years. For this and other reasons-including pirates and geopolitical and environmental reasons-it is widely considered urgent to find new sailing routes.

Once unfeasible on account of sea-ice, the Arctic routes, including the Northeast and Northwest passages (Fig. 2), are now of increasing interest. According to the Intergovernmental Panel on Climate Change, Arctic sea ice has suffered an accelerated decrease due to the significant warming in the region since the 1950s and will continue to diminish in the future (IPCC 2014). Although there are still large uncertainties, model results have indicated that there will be nearly no ice in the Arctic Ocean in
September by the middle of 21 st century (e.g., Overland \& Wang 2013).

Compared with traditional maritime routes through the Panama and Suez canals, the distance from China or Japan to the east coast of North America through the Northwest Passage for general types of ships, including container ships, can save $25 \%$ to $44 \%$ of the total distance, while navigation through the Northeast Passage from Asia to Europe can be $25 \%$ to $55 \%$ shorter (Andersen et al. 1995; Ragner 2000; Zhang et al. 2009).

The economic viability of polar fleets navigating on current routes after months sailing on the Arctic routes and how shipping companies will adapt to the emergence of the shorter Arctic routes are among the issues considered in the Arctic marine shipping assessment 2009 report (Arctic Council 2009). Somanathan et al. (2007, 2009) simulated the economic benefits of container shipping between eastern North America and Japan via the north-west route versus the Panama Canal. Verny \& Grigentin (2009), Chernova \& Volkov (2010) \& Srinath (2010) evaluated and analyzed the economic profitability of container shipping through the NSR. Schøyen \& Bråthen (2011) made a comparison between the NSR and the Suez Canal route, taking into account geography, ship features and navigation cost, and pointed out that 


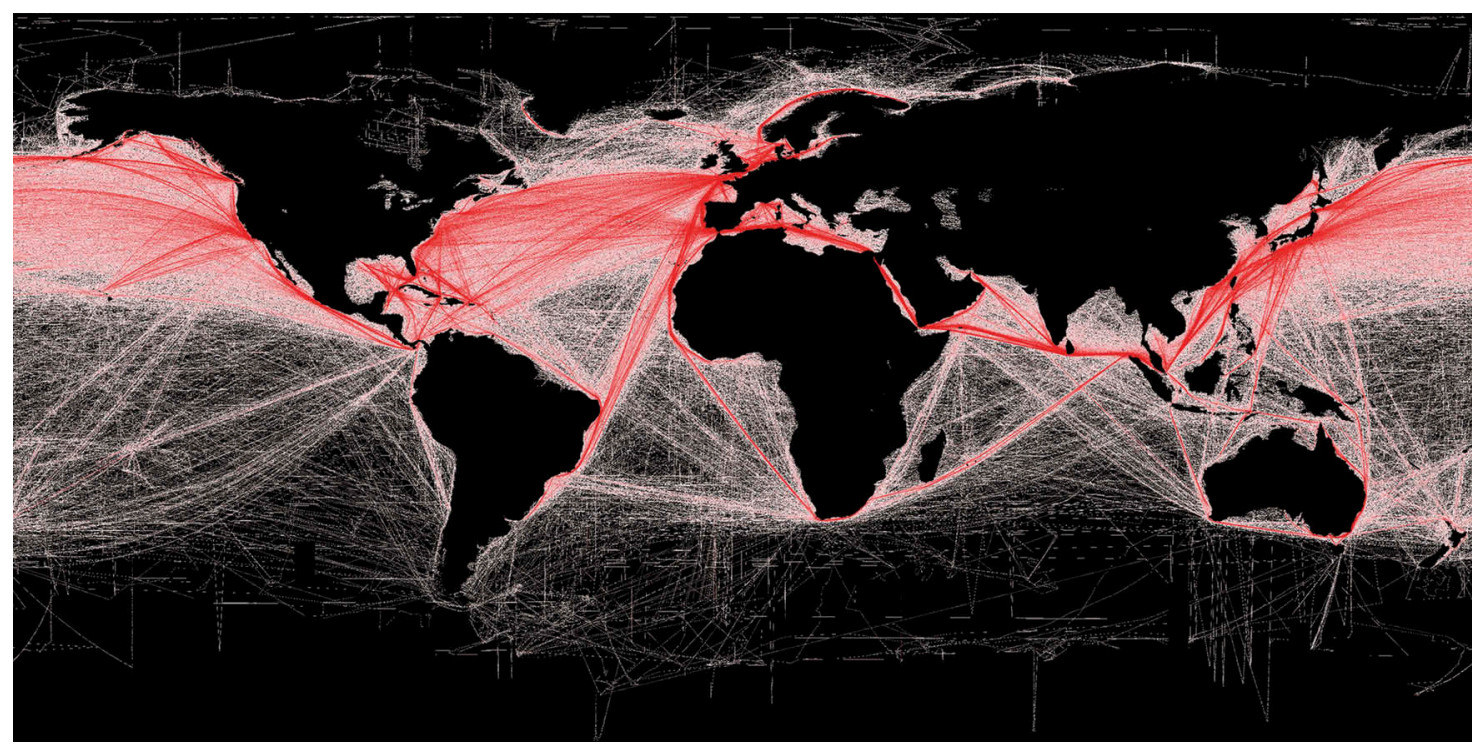

Figure 1. Main maritime shipping routes. (Illustration by B.S. Halpern [T. Hengl; D. Groll], Wikimedia Commons, CC BY-SA 3.0.)

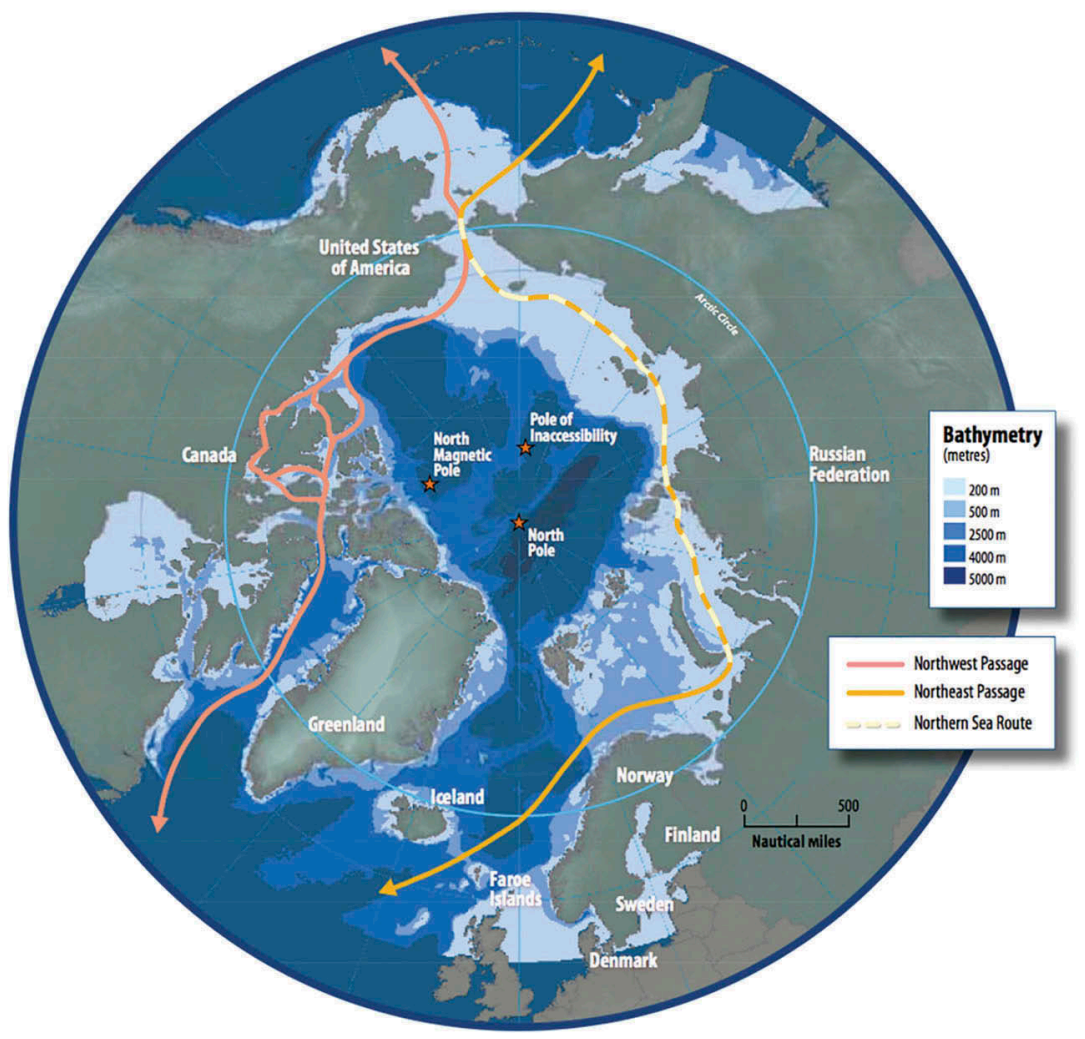

Figure 2. Map of the Arctic region showing the Northeast Passage (including the Northern Sea Route) and the Northwest Passage. (Illustration by Susie Harder, Wikimedia Commons, public domain.)

the added choice of the NSR route may improve adaptability in the global shipping supply chain. Liu \& Kronbak (2010) calculated the economic potential of using the NSR as an alternative route between Asia and Europe based on different sea-ice conditions in the Arctic. Way et al. (2015) added speed optimization into the LKM and adopted a probabilistic simulation approach. These studies (see also reviews by Wergeland et al. 2013, Lasserre 2014 and Zhang et al. 2016) focus on whether it is more economically advantageous to navigate the Arctic routes or to sail the current routes.

Existing models fail to account for a number of important issues. One of these is the assumption that no interaction exists between the Arctic sea routes and the current routes, whereas an obvious competitive relationship exists between the routes relative to any origindestination pair. Also, the existing coupled climate models have great uncertainties in estimating the annual navigable days on the Arctic routes. However, it is 
predictable that the original equilibrium of the container transport industry (Fig. 3) is bound to be seriously disturbed by the opening of the Arctic routes. With incomplete information, can we predict how the global container shipping will change with the rise of the Arctic routes? Game theory is a powerful tool to describe the dynamic equilibrium in the world container shipping market and in this paper we present a game model in Stackelberg form to illustrate the issues mentioned above.

\section{A game model}

As the leaders, shipping companies maximize their profits by speed adjustment in the case of a fixed charge. In their literature review, Tran \& Haasis (2015) pointed out that navigation time and economic cost are two main factors in the optimization of shipping costs, which are closely related to the distance of routes and the speed of ship. Navigation distance is an inherent attribution of route, while the sailing speed manipulated by shipping companies can be taken as a strategy set in this game. Ronen (1982), Wang \& Meng (2012) and Psaraftis \& Kontovas (2013) investigated the relationship between navigation speed and fuel consumption. Corbett et al. (2009), Lang \& Veenstra (2010) and Norstad et al. (2011) further studied the economic effects of ship velocity on shipping costs and illustrated that shipping costs can be effectively reduced by speed adjustment, which is likely to enhance the competitiveness of shipping companies. As the followers, customers choose shipping companies on the basis of the competition results and thereby affect which routes are used (Zhou et al. 2005).

To clarify the model proposed in this paper, consider first a set $I$ of players (shipping companies) in an incomplete game (for model notations, see Table 1). Each shipping company $i \in I$ has its attribution vector (navigable days) OpenWater $(\mathrm{nm})=$ $3.3 \times$ NavigableDays $+6100, \forall c_{i r}^{k} \in C_{i}$, where scenario set $k \in K$, route set $r \in R_{w}$ and $C_{i}=$ $C_{i 1}^{1} \times \ldots \times C_{i r}^{k}$.

For each shipping company, its probability of attribution vector can be written as:

$$
\pi_{i}\left(c_{i}\right)=Z_{i}\left(c_{i} \mid c_{-i}\right)
$$

And the subjective probability distribution can be expressed as:

$$
Z_{i}\left(c_{i} \mid \mathcal{c}_{-i}\right)=Z_{i}\left(c_{i}, c_{-i}\right) / \sum_{c_{-i}} Z_{i}\left(c_{i}, c_{-i}\right)
$$

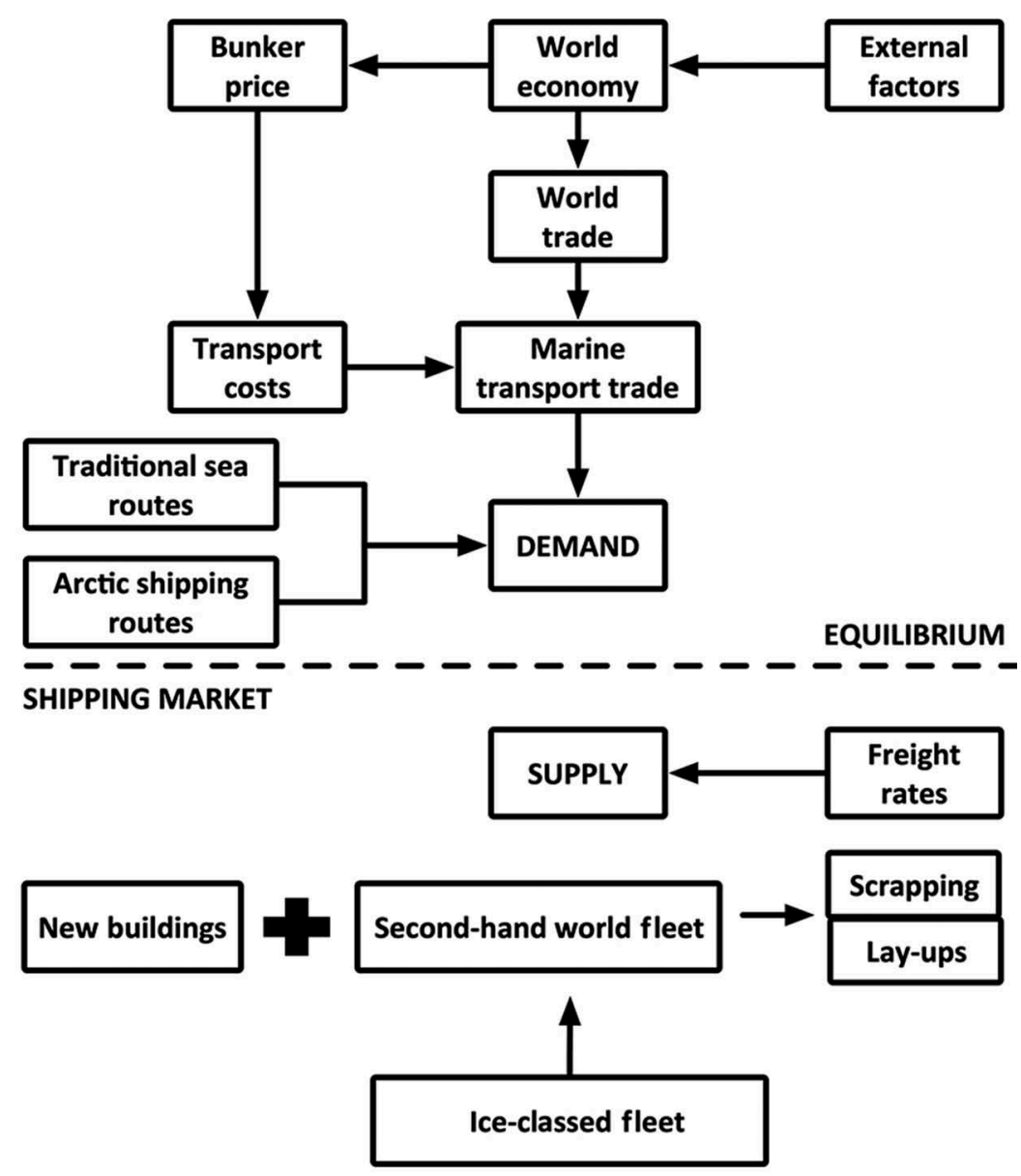

Figure 3. The equilibrium of demand and supply between shipping companies and customers. 
Table 1. Notations used in the model.

\begin{tabular}{|c|c|}
\hline$I$ & set of shipping companies \\
\hline$i$ & an element of set $I$ \\
\hline$W$ & set of all passengers' origin-destination pairs \\
\hline$w$ & an element of set $W$ \\
\hline$R_{w}$ & set of sailing routes between origin-destination pair $w$ \\
\hline$K$ & set of the states of sailing routes \\
\hline$k$ & an element of set $K$ \\
\hline$L_{r}^{k}$ & set of lines on route $r \in R_{w}$ under condition $k \in K$ \\
\hline$S_{i}^{l}$ & distance of line $l \in L_{r}^{k}$ operated by $i$ th company \\
\hline$V_{i}^{l}$ & sailing speed of line $l \in L_{r}^{k}$ operated by $i$ th company \\
\hline $\bar{F}_{i}^{l}$ & standard fuel consumption with standard sailing speed $\bar{V}_{i}^{l}$ \\
\hline$T_{i}^{k}$ & $\begin{array}{l}\text { travel time of a voyage operated by } i \text { th company under } \\
\text { condition } k \in K\end{array}$ \\
\hline$T w_{r}$ & waiting time on route $r \in R_{w}$ \\
\hline$c_{i r}^{k}$ & $\begin{array}{l}\text { navigable time of a voyage operated by } i \text { th company under } \\
\text { condition } k \in K\end{array}$ \\
\hline$D_{r}^{k}$ & $\begin{array}{l}\text { freight volume on sailing route } r \in R_{w} \text { under condition } \\
k \in K\end{array}$ \\
\hline$D^{k}$ & total freight volume under condition $k \in K$ \\
\hline$Q_{i}^{k}$ & $\begin{array}{l}\text { total travel cost of a voyage of } i \text { th company under condition } \\
k \in K\end{array}$ \\
\hline$P_{i}$ & charge of a voyage of $i$ th company under condition $k \in K$ \\
\hline$P c c_{i}^{k}$ & cost of all ships of $i$ th company under condition $k \in K$ \\
\hline$P c_{i}$ & price of a ship of $i$ th company \\
\hline$P v c_{i}^{k}$ & voyage cost of $i$ th company under condition $k \in K$ \\
\hline$P v c_{r}$ & voyage cost on route $r \in R_{w}$ \\
\hline $\operatorname{Poc}_{i}^{k}$ & operating cost of $i$ th company under condition $k \in K$ \\
\hline $\mathrm{Po}_{i}$ & $\begin{array}{l}\text { operating cost per day of } i \text { th company under condition } \\
k \in K\end{array}$ \\
\hline$P f c_{i}^{k}$ & $\begin{array}{l}\text { fuel consumption cost of } i \text { th company under condition } \\
k \in K\end{array}$ \\
\hline Pf & fuel price \\
\hline$C C$ & ship size of $i$ th company \\
\hline
\end{tabular}

The payoff function of shipping company $i$ can be obtained as:

$$
U_{i}=U_{i}\left(s_{1}, \ldots, s_{n}, c_{1}, \ldots, c_{n}\right), \forall s \in S, \forall c \in C,
$$

where $s_{1}, \ldots, s_{n}$ is the strategy set and $S_{i}=S_{1} \times \ldots \times$ $S_{n}$ is the vector space.

Thus the whole Stackelberg model can be seen as an incomplete $\mathrm{n}$ person game that can be written as:

$$
G=\left\{S_{1}, \ldots, S_{n}, C_{1}, \ldots, C_{n}, U_{1}, \ldots, U_{n}, Z_{1}, \ldots, Z_{n}\right\}
$$

From Eqns. 1-3, we have the expected payoff function which is expressed as:

$$
\begin{aligned}
E\left(U_{i}\right) & =\sum_{c_{i}} U_{i}\left(s_{1}^{*}, \ldots, s_{n}^{*}, c_{i}, c_{-i}\right) \pi_{i}\left(c_{i}\right) \\
& =\sum_{c_{i}} U_{i}\left(s_{1}^{*}, \ldots, s_{n}^{*}, c_{i}, c_{-i}\right) \frac{Z_{i}\left(c_{i}, c_{-i}\right)}{\sum_{c_{-i}} Z_{i}\left(c_{i}, c_{-i}\right)}
\end{aligned}
$$

Therefore, the competition process among shipping companies can be described as an optimization problem. For any $i \in I$, we need to solve:

$$
\begin{gathered}
\max _{i \in I}\left\{E\left(U_{i}\right)\right\} \\
s_{i}^{*}=\arg \max _{i \in I}\left\{E\left(U_{i}\right)\right\}
\end{gathered}
$$

Secondly, we note that the payoff function and strategy set of shipping company $i$ in this model depends on other shipping companies' strategy sets. Therefore, the competition between shipping companies can be presented as a generalized Nash equilibrium problem (Debreu 1952), which can be expressed as:

$$
U_{i}=U_{i}\left(s_{i}, s_{-i}\right), \forall s_{i} \in S_{i}\left(s_{-i}\right)
$$

In this paper, Equation (8) can be presented as a structural variational inequality problem and can be solved by the alternating direction method of multipliers based on penalization (Wei et al. 2014).

Finally, when considering the competition results among shipping companies, customers choose the optimal shipping companies and assign the container shipping demand on different routes by a logit-type multi-path assignment model.

\section{Model construction}

\section{Competition mechanism between shipping companies}

Consider that there are Arctic shipping companies, which navigate on the Arctic routes when ice conditions permit it and otherwise navigate on the current routes, and there are non-Arctic shipping companies, which sail on the current routes all the year around.

During a constant navigation circle (usually one year), the average total travel cost per trip, with a given ice-condition scenario, generally includes four parts: the shipbuilding fee, voyage fee, operating cost and fuel consumption cost, which can be obtained as:

$$
Q_{i}^{k}=P c c_{i}^{k}+P o c_{i}^{k}+P c_{i}^{k}+P v c_{i}^{k},
$$

where the average shipbuilding fee per trip under certain a given ice condition can be expressed as:

$$
P c c_{i}^{k}=P c_{i} \times \frac{T_{i}^{k}}{T}, \forall i \in I
$$

$T$ is the navigation circle and $T_{i}^{k}$ can be described by:

$$
T_{i}^{k}=\sum_{r \in R_{w}}\left(T w_{r}+\sum_{l \in l_{r}^{k}} \frac{S_{i}^{l}}{V_{i}^{l}}\right) \frac{c_{i r}^{k}}{T}, \forall k \in K, \forall i \in I
$$

$P o c_{i}^{k}$ can be obtained as:

$$
\operatorname{Poc}_{i}^{k}=P o_{i} \times T_{i}^{k}, \forall k \in K, \forall i \in I
$$

For a given ship type, the fuel consumption per unit distance is proportional to the square of the speed (Dykstra 2005). Therefore, we have:

$$
\begin{gathered}
P f c_{i}^{k}=P f \sum_{r \in R_{w}}\left[\frac{c_{i r}^{k}}{T} \sum_{l \in l_{r}^{k}} \frac{\bar{F}_{i}^{l}}{\left(\bar{V}_{i}^{l}\right)^{2}} S_{i}^{l}\right], \forall k \in K, \\
\forall i \in I, \forall r \in R_{w}
\end{gathered}
$$

Each route has its own voyage fee, which includes such expenses as tolls, ice-breaking fees and pilotage fee, which we obtain as: 


$$
P v c_{i}^{k}=\sum_{r \in R_{w}}\left[\frac{c_{i r}^{k}}{T} P v c_{r}\right], \forall k \in K, \forall i \in I
$$

From Eqns. 9-14, the average total travel cost per trip in the case of given ice conditions can be rewritten as:

$$
\begin{gathered}
Q_{i}^{k}=P c c_{i}^{k}+P o c_{i}^{k}+P f c_{i}^{k}+P v c_{i}^{k} \\
=\left(\frac{P c_{i}}{T}+P o_{i}\right) \sum_{r \in R_{w}}\left[\left(T w_{r}+\sum_{l \in l_{r}^{k}} \frac{S_{i}^{l}}{V_{i}^{l}}\right) \frac{c_{i r}^{k}}{T}\right] \\
+P f \sum_{r \in R_{w}}\left[\frac{c_{i r}^{k}}{T} \sum_{l \in l_{r}^{k}} \frac{\bar{F}_{i}^{l}}{\left(\bar{V}_{i}^{l}\right)^{2}} S_{i}^{l}\right]+\sum_{r \in R_{w}} \frac{c_{i r}^{k}}{T} P v c_{r}, \\
\forall k \in K, \forall i \in I, \forall r \in R_{w}
\end{gathered}
$$

\section{Assignment of container shipping demand}

We employ a logit-type multi-path assignment model, which is widely used in allocation problems to present the assignment mechanism of container shipping demand between the Arctic routes and the current routes. It can be expressed as:

$$
D_{i}^{k}=\frac{e^{-\theta\left(A_{i}^{k}\right)}}{\sum_{i \in I} e^{-\theta\left(A_{i}^{k}\right)}} D^{k}, \forall k \in K, \forall i \in I,
$$

where the actual shipping cost is composed of the charge by shipping company and the navigation time cost, which can be expressed by:

$$
A_{i}^{k}=\lambda P_{i}^{k}+T_{i}^{k}, \forall k \in K, \forall i \in I,
$$

where $\lambda$ is the weight coefficient that reflects the relationship between time cost and economic cost in the actual shipping cost.

\section{Profits of the arctic and non-Arctic shipping companies}

Based on Equation (15), the payoff function (profits) of shipping company $i$ can be rewritten as:

$$
\begin{aligned}
& U_{i}^{k}=\left(P_{i}^{k}-Q_{i}^{k}\right) \times \frac{D_{i}^{k}}{C C}= \\
& \left\{\begin{array}{l}
P_{i}^{k}-\left(\frac{P c_{i}}{T}+P o_{i}\right) \sum_{r \in R_{w}}\left[\left(T w_{r}+\sum_{l \in l_{r}^{k}} \frac{S_{i}^{l}}{V_{i}^{l}}\right) \frac{c_{i r}^{k}}{T}\right]- \\
P f \sum_{r \in R_{w}}\left[\frac{c_{i r}^{k}}{T} \sum_{l \in l_{r}^{k}} \frac{\bar{F}_{i}^{l}}{\left(\bar{V}_{i}^{l}\right)^{2}} S_{i}^{l}\right]-\sum_{r \in R_{w}} \frac{c_{i r}^{k}}{T} P v c_{r}
\end{array}\right\} \\
& \frac{e^{-\theta\left(A_{i}^{k}\right)}}{\sum_{i \in I} e^{-\theta\left(A_{i}^{k}\right)} \frac{D^{k}}{C C}, \forall k \in K, \forall i \in I, \forall r \in R_{w}}
\end{aligned}
$$

And the expectance profits of shipping company $i$ can be expressed as:

$$
\begin{aligned}
& \max _{V_{i}^{l}, D_{i}}\left(U_{i}\right)=\sum_{k \in K}\left(\sum_{r \in R_{w}} Z_{i}\left(c_{i r}^{k} \mid c_{-i r}^{k}\right)\right) U_{i}^{k}= \\
& \sum_{k \in K}\left(\sum_{r \in R_{w}} \pi_{i}\left(c_{i r}^{k}\right)\right) U_{i}^{k}=\sum k \in K\left(\sum_{r \in R_{w}} \pi_{i}\left(c_{i r}^{k}\right)\right) \\
& \left\{\begin{array}{l}
P_{i}^{k}-\left(\frac{P c_{i}}{T}+P o_{i \in R_{w}}\right) \sum\left[\left(T w_{r}+\sum_{l \in l_{r}^{k}} \frac{S_{i}^{l}}{V_{i}^{l}}\right) \frac{c_{i r}^{k}}{T}\right]- \\
P f \sum_{r e R w}\left[\frac{c_{i r}^{k}}{T} \sum_{l \in l_{r}^{k}} \frac{\bar{F}_{i}^{l}}{\left(\bar{V}_{i}^{l}\right)^{2}} S_{i}^{l}\right]-\sum_{r e R w} \frac{c_{i r}^{k}}{T} P v c_{r}
\end{array}\right\} \\
& \frac{e^{-\theta\left(A_{i}^{k}\right)}}{\sum_{i \in I} e^{-\theta\left(A_{i}^{k}\right)} \frac{D^{k}}{C C}, \forall k \in K, \forall i \in I, \forall r \in R_{w}}
\end{aligned}
$$

\section{Solution algorithm}

In the Stackelberg game with incomplete information described above, our goal is to solve the following constrained optimization problem as:

$$
\begin{gathered}
\max U_{i}\left(V_{i}, V_{-i}\right), \forall i \in I \\
h_{i}\left(V_{i}\right) \leq 0
\end{gathered}
$$

$$
g_{i}\left(V_{i}, V_{-i}\right) \leq 0,
$$

where $V_{i}=\left\{V_{i}^{l} \mid l \in L_{r}^{k}, r \in R_{w}, k \in K\right\} \quad$ and $V_{-i}$ $=\left\{V_{-i}^{l} \mid l \in L_{r}^{k}, \quad r \in R_{w}, k \in K\right\}$

This generalized Nash equilibrium problem was first solved using the penalty function optimization method developed by Pang \& Fukushima (2009), reducing generalized Nash equilibrium problem to a standard Nash equilibrium problem. Therefore, Eqns. 20-22 can be rewritten as:

$$
\min \left\{-U_{i}\left(V_{i}, V_{-i}\right)-\frac{1}{\rho} \sum_{j=1}^{n_{j}} \log \left(-g_{i}^{j}\left(V_{i}, V_{-i}\right)\right)\right\}
$$

$$
\begin{gathered}
h_{i}\left(V_{i}\right) \leq 0 \\
\text { s.t. } g_{i}\left(V_{i}, V_{-i}\right) \leq 0
\end{gathered}
$$

Equations 23-25 are equivalent to finding solutions of a variational inequality problem, such that

$$
\begin{aligned}
& \left(\mathrm{V}-\mathrm{V}^{*}\right)^{T}\left(F\left(\mathrm{~V}^{*}\right)+G\left(\mathrm{~V}^{*}\right)\right) \geq 0, \forall \mathrm{V} \\
& \quad=\left(\mathrm{V}_{i}, \mathrm{~V}_{-i}\right) \in \Xi
\end{aligned}
$$


where:

$$
\begin{gathered}
F(\mathrm{~V})=\left(\nabla_{V_{i}}\left(-U_{i}\left(\mathrm{~V}_{i}, \mathrm{~V}_{-i}\right)\right)\right)_{i=1}^{N} \\
G(\mathrm{~V})=\left(-\frac{1}{\rho} \sum_{j=1}^{n_{j}} \frac{\nabla_{V_{i}} g_{i}^{j}\left(\mathrm{~V}_{i}, \mathrm{~V}_{-i}\right)}{g_{i}^{j}\left(\mathrm{~V}_{i}, \mathrm{~V}_{-i}\right)}\right)_{i=1}^{N} \\
\left(x-x^{*}\right)^{T} F\left(x^{*}\right)+ \\
\left(y-y^{*}\right)^{T} G\left(y^{*}\right) \geq 0, \forall(x, y) \in \Omega,
\end{gathered}
$$

where

$$
\begin{gathered}
\left.\Omega=\{(\mathrm{x}, \mathrm{y})\} \in \Xi \times \mathbb{R}^{n} \mid x-y=0\right\} \\
L_{\rho}=\left(z-z^{*}\right) H\left(z^{*}\right) \geq 0, \forall z \in \mathbb{Z},
\end{gathered}
$$

where

$$
\begin{aligned}
& z=\left(\begin{array}{l}
x \\
y \\
\lambda
\end{array}\right), \mathrm{H}(\mathrm{z})=\left(\begin{array}{c}
F(x)-\lambda \\
G(y)+\lambda \\
x-y
\end{array}\right), \\
& \mathbb{Z}=\Xi \times \mathbb{R}^{n} \times \mathbb{R}^{n}
\end{aligned}
$$

The purpose of this paper therefore becomes to solve a structural variational inequality problem and can be solved by the alternating direction method of multipliers with penalization (see Fig. 4). In this algorithm, two sub-problems are solved by a modified extragradient method (Bnouhachem et al. 2009) and the convergence criterion $J^{k}$ is strictly proved by Wei et al. (2014).

\section{Numerical experiment}

The proposed model and algorithm are used to simulate the economic potential of the NSR compared to the Suez Canal route between Asia and Europe (see Fig. 5), as the LKM did using practical data and a scenario analysis method. The simulated scenarios and data first used in the LKM are as follows. From Yokohama to Rotterdam, the navigation distance via the NSR is 7100 nautical miles, whereas the current route via the Suez Canal is 11 460 miles. The navigable days on the NSR per year are assumed to be 91 days in Scenario 1, 182 days in Scenario 2 and 274 days in Scenario 3. The maximum speed of a ship in open water is no more than 25 knots while in ice-covered water it is less than 10 knots. The fuel price is assumed to be 250 USD per tonne. In open water, the standard

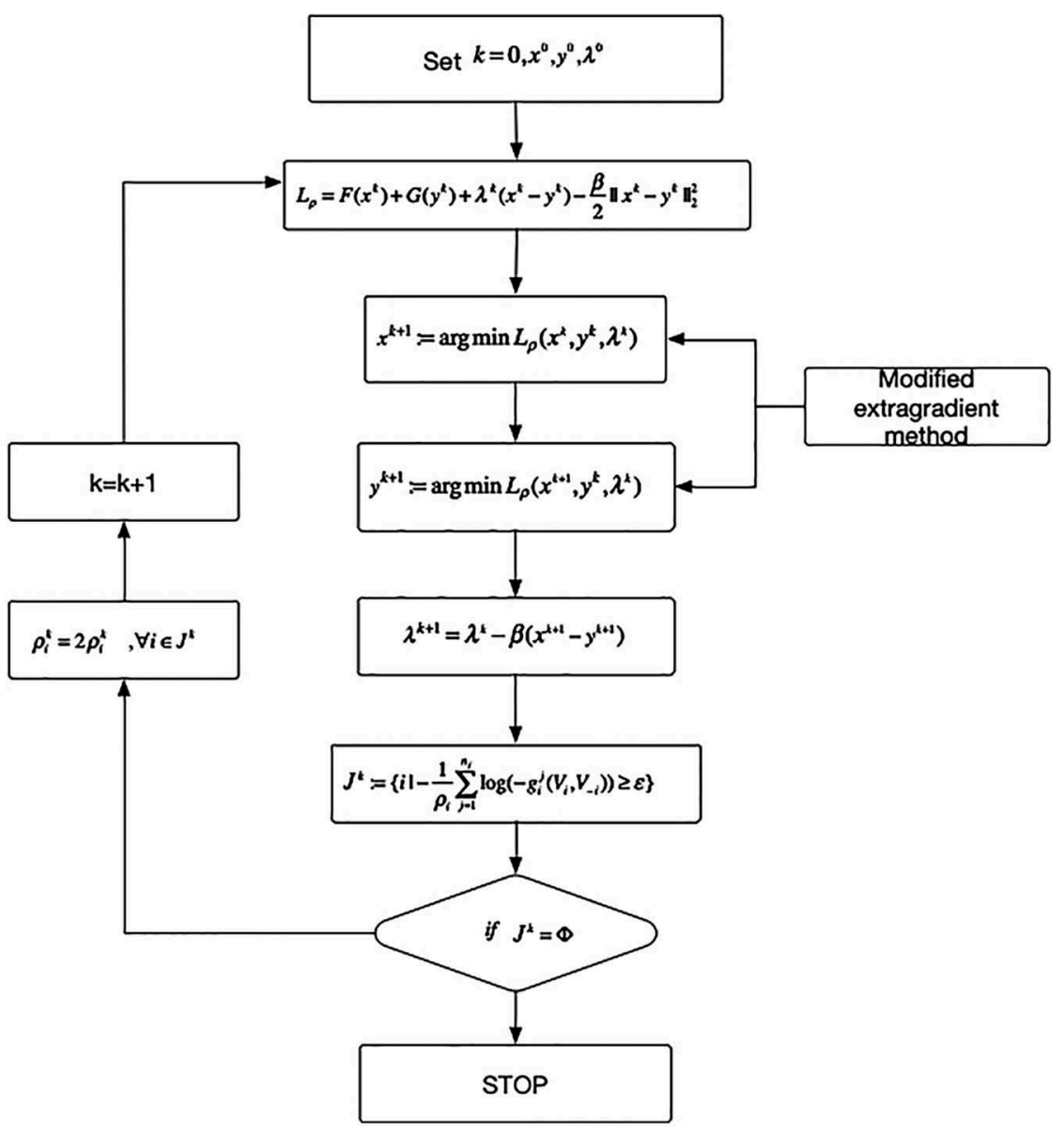

Figure 4. Algorithm flow of the alternating direction method of multipliers with penalization. 


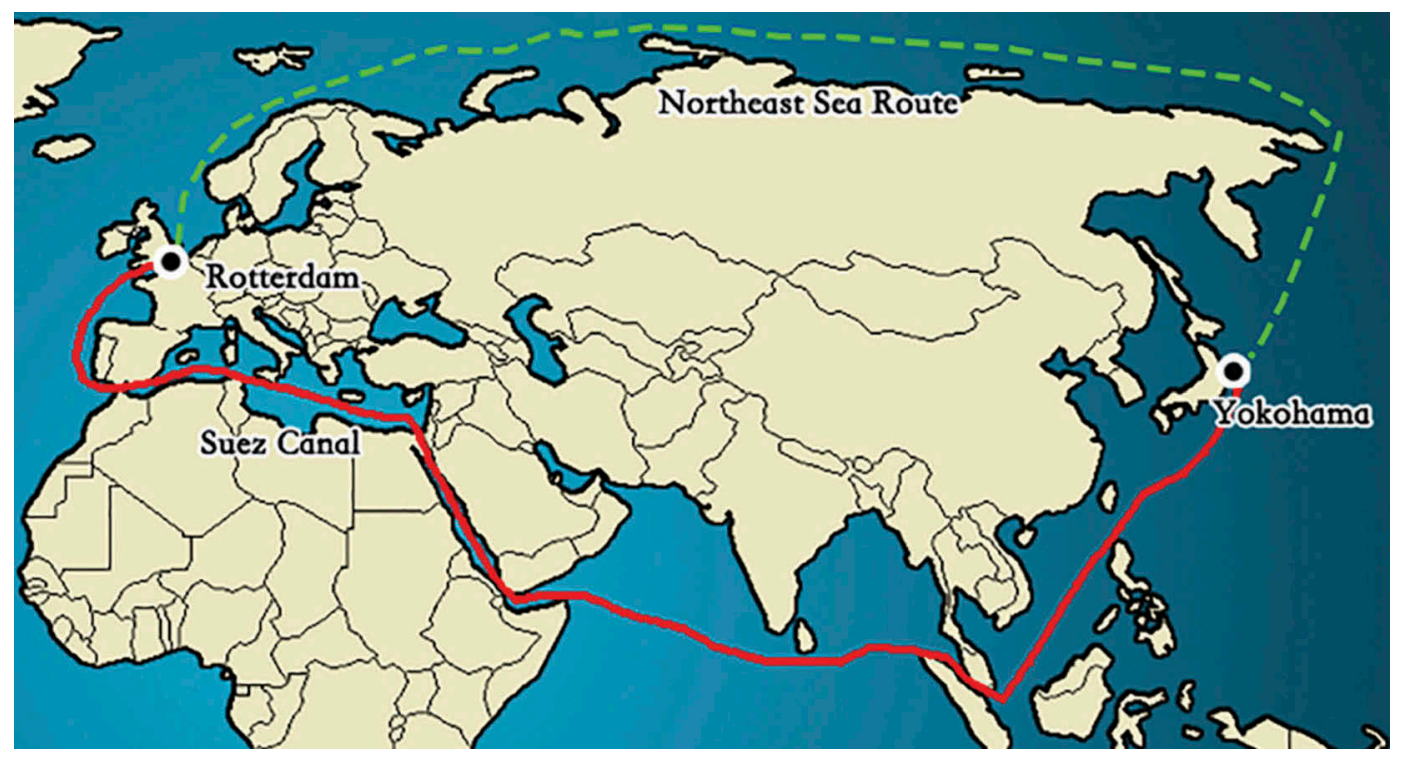

Figure 5. The NSR and the current route via Suez Canal.

fuel consumption is 0.5 ton/nautical mile at 18 knots, while in ice-covered water the standard fuel consumption is 0.3 tonne/nautical mile at 10 knots. The average pilotage and ice-breaking fee in the NSR is 446000 USD per transit. The voyage fee via the Suez Canal is 240800 USD per trip. The price of a ship with 4300 TEU on the NSR is 5.28 million USD, whereas a ship with the same cargo capacity using the Suez Canal is 4.4 million USD. The operating cost (including crew, hull and machinery insurance, protection and indemnity insurance, repairs and maintenance, administration, etc.) on the NSR route is 8925 USD per day, whereas on the Suez Canal route it is 6100 USD per day. The expected charges of all shipping companies are assumed to be the same: 3 million USD per trip. The total container shipping demand is 4.3 million TEU per year. The relationship between navigable days and the length of open water can be expressed as:

$$
\begin{aligned}
\operatorname{OpenWater}(\mathrm{nm})= & 3.3 \times \text { NavigableDays } \\
& +6100
\end{aligned}
$$

The experimental data and hypotheses mentioned above are substituted into the proposed model where two equilibriums are presented. The first equilibrium, which is the competition result among shipping companies that navigate via the Suez Canal before the NSR opening, is Stage 1. Stage 2 represents another equilibrium: the result of the competition among shipping companies with the opening of the NSR. In Stage 2, some shipping companies begin to sail on the NSR while others stay on the current route via the Suez Canal. The game begins in
Stage 1. Each company maximizes its profits through speed adjustment, which can reduce the total travel cost and attract more customer demand. Finally, the new equilibrium in Stage 2 is reached.

It is hard to use mathematic means to prove the convexity of the payoff function due to its complex formulation. However, by simulation, the convergence of the proposed algorithm in our model is shown in Fig. 6 and stable solutions can be obtained.

The profits of the Arctic and non-Arctic shipping companies before speed adjustment are represented by the LKM while our model represents the profits after speed adjustment in the case of three different scenarios. The profits of each scenario and their expectations are presented in Fig. 7. The adjustment speed can be seen in Table 2. From Fig. 7 and Table 1, we can see the speeds on each line route (including the Suez Canal, ice-covered NSR and open-water NSR) decrease while the profits of each company increase after speed adjustment. The expectation profits of the non-Arctic companies have rise by $18.1 \%$ (Scenario 1: $20.3 \%$, Scenario 2: $17.8 \%$, Scenario 3: $15.1 \%$ ) and that of the Arctic companies have rise by $14 \%$ (Scenario 1: 20.3\%, Scenario 2: $14.1 \%$, Scenario 3: $9.6 \%$ ). That is to say, the optimization of the navigation speed helps to boost the profits of shipping companies in our proposed model.

With more navigable days on the NSR, the maximum profits change of the Arctic and non-Arctic shipping companies during two stages and the features of container flow are shown in Fig. 8. We can see from Fig. 8 that there are no navigable days on the NSR in the original state, i.e., Stage 1, when all the container shipping companies navigate via the Suez Canal. As the navigable days increase on the NSR, the maximum profits of the non-Arctic 

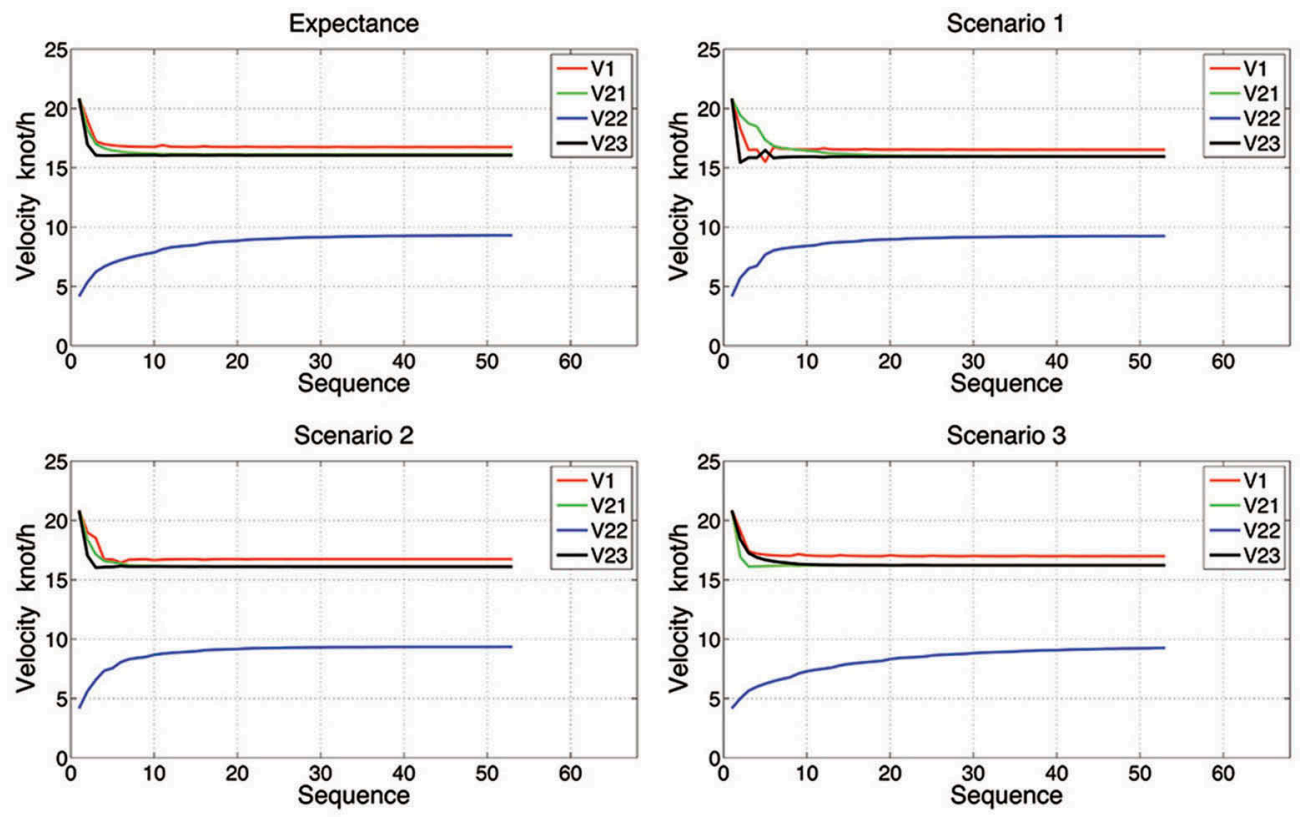

Figure 6. Convergence of the proposed algorithm in our model.

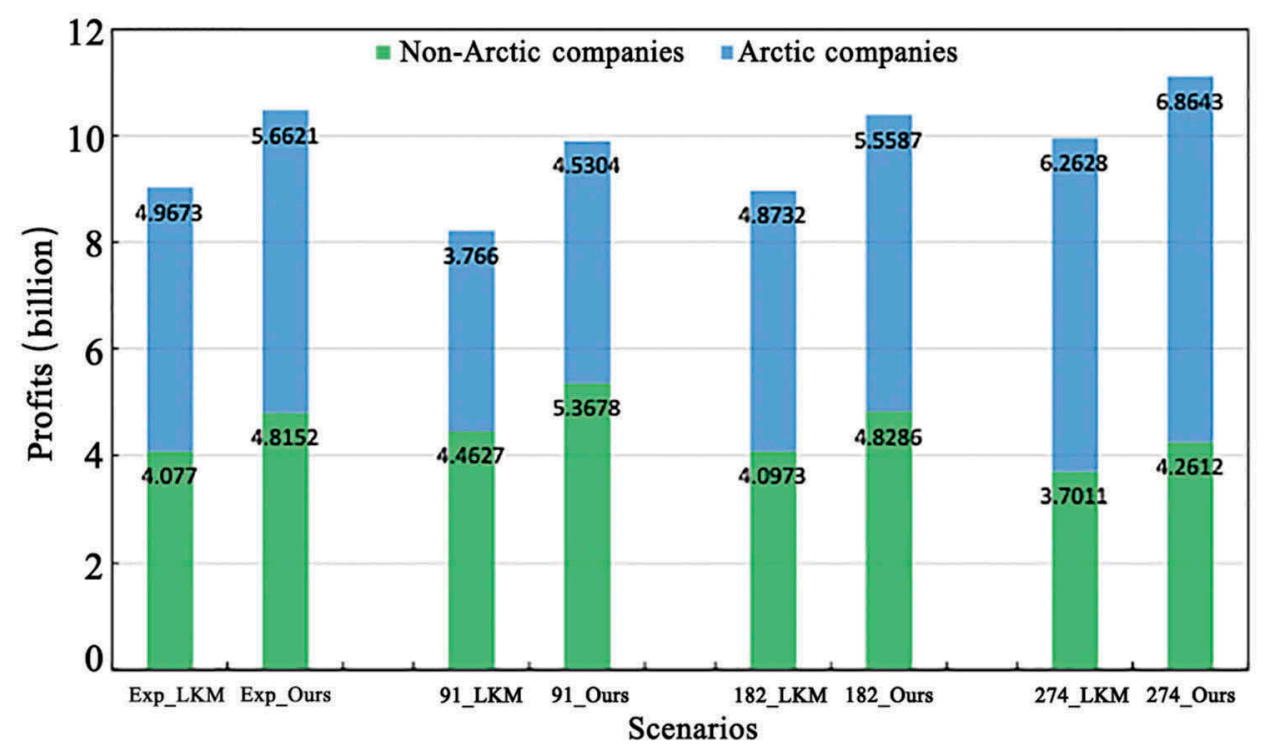

Figure 7. Comparison between LKM and our model.

Table 2. Navigation speeds in the LKM and our model. Values in the NAC column represent the sailing speeds of ships from non-Arctic companies. Values in the ARC columns represent the sailing speeds of ships from Arctic companies on an open and ice-covered NSR and open water via the Suez Canal.

\begin{tabular}{|c|c|c|c|c|c|c|c|c|}
\hline \multirow[b]{2}{*}{$\begin{array}{l}\text { Scenarios } \\
\text { Models }\end{array}$} & \multicolumn{2}{|c|}{$\begin{array}{c}\text { Mean } \\
(\text { knot/h) }\end{array}$} & \multicolumn{2}{|c|}{$\begin{array}{c}91 \\
\text { (knot/h) }\end{array}$} & \multicolumn{2}{|c|}{$\begin{array}{c}182 \\
(\mathrm{knot} / \mathrm{h})\end{array}$} & \multicolumn{2}{|c|}{$\begin{array}{c}274 \\
\text { (knot/h) }\end{array}$} \\
\hline & NAC & ARC & NAC & ARC & NAC & ARC & NAC & ARC \\
\hline LKM & 18 & $18,10,18$ & 18 & $18,10,18$ & 18 & $18,10,18$ & 18 & $18,10,18$ \\
\hline Ours & 16.7 & $16.1,9.3,16$ & 16.5 & $15.9,9.3,15.9$ & 16.8 & $16.1,9.4,16.1$ & 17 & $16.2,9.4,16.2$ \\
\hline
\end{tabular}

companies present a tendency to increase first and then to decrease while the Arctic companies present the opposite trend. The results illustrate that with the opening of the NSR, it gradually shows a higher economic potential than the Suez Canal. In addition, the proportion of container demand on the NSR increases with the increased navigable days. When NSR is entirely open, the container volume on the NSR will account for more than $60 \%$ of the total, which also highlights the higher economic potential on the NSR than that of the Suez Canal. 


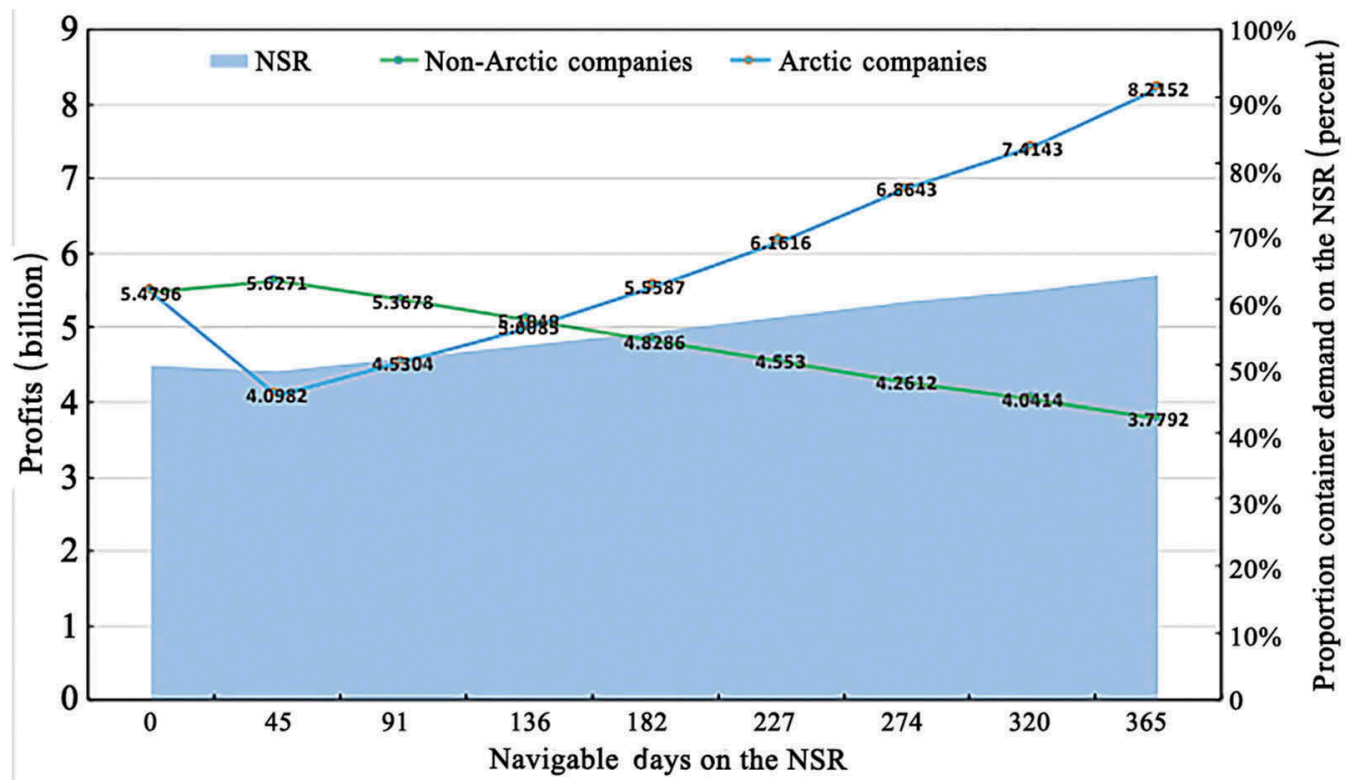

Figure 8. Variation in shipping company profits and NSR container demand with changes in the number of navigable days in the NSR.

\section{Conclusion}

Simulating the economic potential of the sea routes through the Northeast Passage and the Suez Canal, our model predicts that it will be increasingly profitable for shipping companies to use the NSR and that traffic on this route will grow as sea-ice diminishes. However, the international shipping of container cargo is shaped by many other factors than those considered in this model, including the world economy, politics, environmental considerations other than sea ice and technological developments.

\section{Acknowledgements}

The authors thank the reviewers, whose efforts improved this paper.

\section{Disclosure statement}

No potential conflict of interest was reported by the authors.

\section{Funding}

This work was supported by the National Natural Science Foundation of China (grant nos. 51609254 and 41375002.)

\section{References}

Andersen O., Heggeli T. \& Wergeland T. 1995. Assessment of potential cargo from and to Europe via the NSR. INSROP Working Paper 11-1995. Lysaker, Norway: International Northern Sea Route Programme Secretariat, Fridtjof Nansen Institute.
Arctic Council 2009. Arctic marine shipping assessment 2009 report. Tromsø, Norway: Protection of the Arctic Marine Environment Working Group, Arctic Council.

Bnouhachem A., Xu M.H., Fu X.L. \& Sheng Z. 2009. Modified extragradient methods for solving variational inequalities. Computers \& Mathematics with Applications 57, 230-239.

Chernova S. \& Volkov A. 2010. Economic feasibility of the Northern Sea Route container shipping development. Master's thesis, Bodø University College, Bodø, Norway. Corbett J.J., Wang H. \& Winebrake J.J. 2009. The effectiveness and costs of speed reductions on emissions from international shipping. Transportation Research Part D: Transport and Environment 14, 593-598.

Debreu G. 1952. A social equilibrium existence theorem. Proceedings of the National Academy of Sciences of the USA 38, 886-893.

Dykstra D.L. 2005. Commercial management in shipping. London: Nautical Institute.

He B., Liao L.Z., Han D. \& Yang H. 2002. A new inexact alternating directions method for monotone variational inequalities. Mathematical Programming 92, 103-118.

IPCC (Intergovernmental Panel on Climate Change) 2014. Climate change 2014: synthesis report. Contribution of Working Groups I, II and III to the fifth assessment report of the Intergovernmental Panel on Climate Change. Core Writing Team, R.K. Pachauri \& L.A. Meyer (eds.). Geneva: Intergovernmental Panel on Climate Change

Lang N. \& Veenstra A. 2010. A quantitative analysis of container vessel arrival planning strategies. OR Spectrum 32, 477-499.

Lasserre F. 2014. Case studies of shipping along Arctic routes. Analysis and profitability perspectives for the container sector. Transportation Research Part A: Policy and Practice 66, 144-161.

Liu M. \& Kronbak J. 2010. The potential economic viability of using the Northern Sea Route (NSR) as an alternative route between Asia and Europe. Journal of Transport Geography 18, 434-444.

Norstad I., Fagerholt K. \& Laporte G. 2011. Tramp ship routing and scheduling with speed optimization. Transportation Research Part C: Emerging Technologies 19, 853-865. 
Omre A. 2012. An economic transport system of the next generation integrating the northern and southern passages. Master's thesis, Department of Marine Technology, Norwegian University of Science and Technology, Trondheim.

Overland J.E. \& Wang M. 2013. When will the summer be nearly sea ice free? Geophysical Research Letters 40, 2097-2101.

Pang J.S. \& Fukushima M. 2009. Quasi-variational inequalities, generalized Nash equilibria, and multi-leaderfollower games. Computational Management Science 6, 373-375.

Psaraftis H.N. \& Kontovas C.A. 2013. Speed models for energy-efficient maritime transportation: a taxonomy and survey. Transportation Research Part C: Emerging Technologies 26, 331-351.

Ragner C.L. 2000. Northern sea route cargo flows and infrastructure-present state and future potential. FNI Report 13/2000. Lysaker, Norway: Fridtjof Nansen Institute.

Ronen D. 1982. The effect of oil price on the optimal speed of ships. Journal of the Operational Research Society 33, 1035-1040.

Schøyen H. \& Bråthen S. 2011. The Northern sea route versus the Suez Canal: cases from bulk shipping. Journal of Transport Geography 19, 977-983.

Somanathan S., Flynn P. \& Szymanski J. 2009. The Northwest Passage: a simulation. Transportation Research Part A: Policy and Practice 43, 127-135.

Somanathan S., Flynn P.C. \& Szymanski J.K. 2007. Feasibility of a sea route through the Canadian Arctic. Maritime Economics \& Logistics 9, 324-334.

Srinath B.N. 2010. Arctic shipping: commercial viability of the Arctic sea routes. Master's thesis, Department of Hydraulic Engineering, City University, London.

Talley W.K. \& Ng M.W. 2013. Maritime transport chain choice by carriers, ports and shippers. International Journal of Production Economics 142, 311-316.

Tran N.K. \& Haasis H.D. 2015. Literature survey of network optimization in container liner shipping. Flexible Services and Manufacturing Journal 27, 139-179.
UNCTAD (United Nations Conference on Trade and Development) 2013. Review of maritime transport 2013. Geneva: United Nations.

Verny J. \& Grigentin C. 2009. Container shipping on the northern sea route. International Journal of Production Economics 122, 107-117.

Wang S. \& Meng Q. 2012. Sailing speed optimization for container ships in a liner shipping network. Transportation Research Part E: Logistics and Transportation Review 48, 701-714.

Way B., Khan F. \& Veitch B. 2015. The Northern Sea Route vs the Suez Canal Route: an economic analysis incorporating probabilistic simulation optimization of vessel speed. In: ASME 2015 34th International Conference on Ocean, Offshore and Arctic Engineering. Vol. 8. Ian Jordaan Honoring Symposium on Ice Engineering. St. John's, Newfoundland, Canada, May 31-June 5, 2015. Pp. V008T07A010-V008T07A010. New York: American Society of Mechanical Engineers.

Wei Y.Y., Lingling X.U. \& Han D.R. 2014. A decomposition method based on penalization for solving generalized Nash equilibrium problems. Scientia Sinica 44, 295.

Wergeland T. 2013. Northeast, Northwest and Transpolar passages in comparison. In W. Østreng et al. (eds.): Shipping in Arctic waters: a comparison of the Northeast, Northwest and Trans Polar passages. Pp. 299-352. Berlin: Springer-Praxis.

Zhang X., Jing-Fang T.U., Guo P.Q., Sun K. \& Ling X.L. 2009. The economic estimate of Arctic Sea routes and its strategic significance for the development of chinese economy. China Soft Science 2009-S2. 86-93.

Zhang Y., Meng Q. \& Ng SH 2016. Shipping efficiency comparison between Northern Sea Route and the conventional Asia-Europe shipping route via Suez Canal. Journal of Transport Geography 57, 241-249.

Zhou J., Lam W.H.K. \& Heydecker B.G. 2005. The generalized Nash equilibrium model for oligopolistic transit market with elastic demand. Transportation Research Part B 39, 519-544. 